\title{
Recién nacido hijo de una madre con leptospirosis: reporte de caso
}

Luz Cisneros-Infantas ${ }^{1,2}$; Víctor Peralta-Chávez ${ }^{1,2}$; Joshuan J. Barboza-Meca* 3

RESUMEN

La leptospirosis humana es una enfermedad causada por bacterias del género Leptospira. Las leptospiras infectan al organismo a través de la piel y mucosas lesionadas. En el sitio de ingreso producen poca reacción inflamatoria local. Los síntomas clínicos varían desde un cuadro parecido a la gripe, hasta ictericia o incluso falla renal y hepática, y están asociados con altas tasas de mortalidad. Se sabe que hay una infección transplacentaria que puede provocar un aborto espontáneo, muerte fetal o leptospirosis congénita. El aborto espontáneo es más común si la infección ocurre en los primeros meses del embarazo. El objetivo de este reporte de caso es dar a conocer la presentación, manifestaciones y abordaje terapéutico en cuidados intensivos de un recién nacido con antecedente materno de leptospirosis en el primer trimestre de embarazo, así como la revisión de la literatura con estructura de búsqueda sistemática.

Palabras clave: Leptospira; Leptospirosis; Recién nacido (Fuente: DeCS BIREME).

\section{Newborn infant of a mother with leptospirosis: a case report}

\section{ABSTRACT}

Human leptospirosis is a disease caused by bacteria of the genus Leptospira. Leptospiras infect the body through the skin and damaged mucous membranes. At the site of admission, they produce little local inflammatory reaction. Clinical symptoms range from flu-like symptoms to jaundice or even kidney and liver failure, and are associated with high mortality rates. It is known that there is a transplacental infection that can cause miscarriage, fetal death or congenital leptospirosis. Miscarriage is more common if the infection occurs in the first months of pregnancy. The objective of this case report is to disclose the presentation, manifestations and therapeutic approach in intensive care of a newborn infant with maternal history of leptospirosis in the first trimester of pregnancy, as well as the review of the literature using a systematic search.

Keywords: Leptospira; Leptospirosis; Newborn (Source: MeSH NLM).

1. Hospital Belén de Trujillo, Servicio de Neonatología. Trujillo, Perú.

2. Universidad Privada Antenor Orrego, Facultad de Medicina Humana, Escuela de Postgrado. Trujillo, Perú.

3. Red Latinoamericana de Pediatría y Neonatología. México.

* Autor corresponsal. 


\section{INTRODUCCIÓN}

La leptospirosis humana es una enfermedad causada por bacterias del género Leptospira ${ }^{(1)}$. En seres humanos, se consideran patógenas como $L$. interrogans y no patógenos como L. biflexa ${ }^{(2)}$. El complejo interrogans, se subdivide en aproximadamente 180 serotipos, los cuales se han dividido en 18 subgrupos. Entre los más comunes se encuentran $L$. icterohaemorrhagiae, $L$. autumnalis, L. canicola, L. pomona, L. australis, $L$. grippotyphosa ${ }^{(3)}$.

Estas bacterias tienen forma de espirales muy finos de 5-18 $\mu \mathrm{m}$ de longitud y 0,1-0,2 $\mu \mathrm{m}$ de ancho. Forman una especie de gancho aerobio que le ha permitido diferenciarse de otras especies de espiroquetas patógenas ${ }^{(4)}$.

La leptospira tiene una distribución mundial, pero es más común en los trópicos donde las condiciones para su transmisión son particularmente favorables ${ }^{(5)}$. Es considerada una enfermedad ocupacional que afecta a personas que se dedican a la agricultura, limpieza de desagües, minería y a quienes están en contacto con animales como los matarifes y los veterinarios ${ }^{(6)}$. En la actualidad la enfermedad ya no solo se circunscribe en los trópicos, puesto que con la globalización, los cambios climáticos y migracionales de animales y personas, la bacteria se ha diseminado en muchas regiones ${ }^{(7)}$.

La prevalencia de diferentes serovares leptospirales dentro de una población humana depende del reservorio de animales presentes y de los serovares que llevan, así como de las condiciones ambientales locales, la ocupación, las prácticas agronómicas y agrícolas ${ }^{(8)}$.

La prevalencia de leptospirosis en Europa oscila entre $8 \%$ en poblaciones asintomáticas no expuestas y $18 \%$ en las expuestas. En Asia, en poblaciones expuestas, la prevalencia encontrada sobrepasa a $35 \%{ }^{(8)}$.

Según reportes de la Dirección General de Epidemiología (DGE), hasta la semana epidemiológica 40 , el número total de casos por leptospirosis fue de 2386, que representan 450 casos más respecto a la media de casos desde el 2013 al $2018^{(9)}$.

Las leptospiras infectan al organismo a través de la piel y mucosas lesionadas. En el sitio de ingreso producen poca reacción inflamatoria local. Después de penetrar la piel o las mucosas, se genera una bacteriemia y se producen anticuerpos aglutinantes y opsonización por lgG específica de serogrupo ${ }^{(10)}$. Después de este proceso, las bacterias son fagocitadas y destruidas por neutrófilos y por monocitos. Si esta respuesta no es suficiente para detener su progreso, la leptospira avanza en los tejidos para multiplicarse en forma acelerada (11).

Los síntomas clínicos varían desde manifestaciones parecidas a la gripe hasta ictericia o incluso falla renal y hepática, y están asociados con altas tasas de mortalidad (12). Las leptospiras se transportan en la sangre y se depositan en todas las partes del cuerpo, incluido el líquido cefalorraquídeo y el ojo. Se sabe que hay una infección transplacentaria que puede provocar un aborto espontáneo, muerte fetal o leptospirosis congénita (13). El aborto espontáneo es más común si la infección ocurre en los primeros meses del embarazo ${ }^{(14,15)}$.

El objetivo de este reporte de caso es dar a conocer la presentación, manifestaciones y abordaje terapéutico en cuidados intensivos de un recién nacido con antecedente materno de leptospirosis en el primer trimestre de embarazo, así como la revisión de la literatura con estructura de búsqueda sistemática.

\section{CASO CLÍNICO}

Neonato de 37 semanas de edad gestacional de sexo masculino, nacido de forma espontánea (vaginal) el 23 de julio del 2018 a las 08:01 horas en el Hospital Belén de Trujillo. Apgar de puntuación 8 al minuto y 9 a los 5 minutos, con $2714 \mathrm{~g}$ de peso, $46 \mathrm{~cm}$ de talla y $32 \mathrm{~cm}$ de perímetro cefálico. Tipo de sangre A factor Rh positivo al igual que la madre. Hijo de una madre adulta joven de 19 años, primigesta, originaria de la ciudad de Trujillo, soltera y con estudios secundarios completos. En la historia clínica materna gestas: 0; abortos: 0; partos: 0 . El principal antecedente materno fue el diagnóstico de leptospirosis en el primer trimestre de embarazo, por el que recibió tratamiento.

Entre los antecedentes familiares de la madre figuran las enfermedades infecciosas. No recibió vacuna antitetánica y sólo tiene 1 examen de serología luética (con resultado negativo). Hemoglobina tomada al tercer mes de $10,0 \mathrm{~g} / \mathrm{dL}$ y al sexto mes $10,5 \mathrm{~g} / \mathrm{dL}$. No recibió medicación durante el parto.

El paciente recibió atención inmediata al nacimiento, ingresó a la unidad de alojamiento conjunto, acompañado de su madre con temperatura $36,8{ }^{\circ} \mathrm{C}$, frecuencia respiratoria (FR) 54 por minuto, frecuencia cardiaca (FC) 133 por minuto, saturación de oxígeno $100 \%$ al aire ambiente. A las 12 horas de nacido empieza, de forma repentina, un cuadro respiratorio caracterizado por 
dificultad respiratoria (con tiraje intercostal, aleteo nasal, cianosis), taquicardia (FC: 140 por minuto), taquipnea (FR: 80 por minuto) y desaturación (Sat 02 $88 \%)$. En función de estas manifestaciones se indica CPAP nasal (PEEP $5 \mathrm{cmH}_{2} \mathrm{O}$ ) y se inicia con tratamiento antibiótico (ampicilina y amikacina) ante una sospecha de sepsis, previa toma de muestra sanguínea para gasometría, glucosa sérica, hemograma (Tabla 1), PCR y bilirrubina sérica (PCR 17,6 mg/dL; bilirrubina total de $12,72 \mathrm{mg} / \mathrm{dL}$ ), motivo por el cual es ingresado en la unidad de cuidados intensivos neonatales.

A las 11 horas del 24 de julio empieza una alteración de la función neurológica que se evidencia con hipotonía (no hipoglucémica) y signos meníngeos, por lo que se solicita punción lumbar para analizar líquido cefalorraquídeo (Tabla 2), además de ecografía transfontanelar (Figuras 1 y 2). Se agregan al cuadro petequias en tórax, abdomen y brazos, sangrado por sonda orogástrica y empeoramiento del cuadro general, por lo que se sospecha de leptospirosis congénita. A las 12:30 horas del mismo día, se inicia ventilación mecánica invasiva (VM/AC; PIP 17; PEEP 5; $\mathrm{FiO}_{2} 60$ \%; flujo 8L) con tubo endotraqueal, sedación con fentanilo y se inicia tratamiento con vasopresores (dopamina, dobutamina) pero fallece a las 13 horas.

Tabla 1. Número de publicaciones científicas en temas médicos y de la salud de las universidades peruanas

\begin{tabular}{|lcc|}
\hline \multicolumn{1}{c}{ Hemograma } & Valor & Unidad de medida \\
\hline Recuento de glóbulos blancos & 26,77 & $10^{3} / \mathrm{uL}$ \\
\hline VCM & 11,4 & $\mathrm{fL}$ \\
\hline Plaquetas & 48 & $10^{3} / \mathrm{uL}$ \\
\hline Neutrófilos & 12,8 & $10^{3} / \mathrm{uL}$ \\
\hline Linfocitos & 7,56 & $10^{3} / \mathrm{uL}$ \\
\hline Monocitos & 4,48 & $10^{3} / \mathrm{uL}$ \\
\hline Eosinófilos & 0,32 & $10^{3} / \mathrm{uL}$ \\
\hline Basófilos & 0,11 & $10^{3} / \mathrm{uL}$ \\
\hline Abastonados & 10 & $\%$ \\
Segmentados & 42 & $\%$ \\
Neutrófilos & 52 & $\%$ \\
\hline Eosinófilos & - & $\%$ \\
\hline Basófilos & - & $\%$ \\
\hline Monocitos & 12 & $\%$ \\
\hline Linfocitos & 34 & $\%$ \\
\hline
\end{tabular}

* Los valores obtenidos corresponden a las 12 horas de nacido.

Tabla 2. Examen de líquido cefalorraquídeo (LCR)

\begin{tabular}{|lc|}
\hline \multicolumn{1}{c}{ Características } & Valor \\
\hline Proteínas & No \\
\hline Cantidad & $10 \mathrm{ml}$ \\
\hline Color & Sanguinolento \\
Aspecto & Turbio \\
Recuento de células & $30 / \mathrm{mm} 3$ \\
PMN & $5 \%$ \\
\hline Monocitos & $95 \%$ \\
\hline
\end{tabular}

\footnotetext{
* Resultados de laboratorio de 24 horas de nacido.
} 


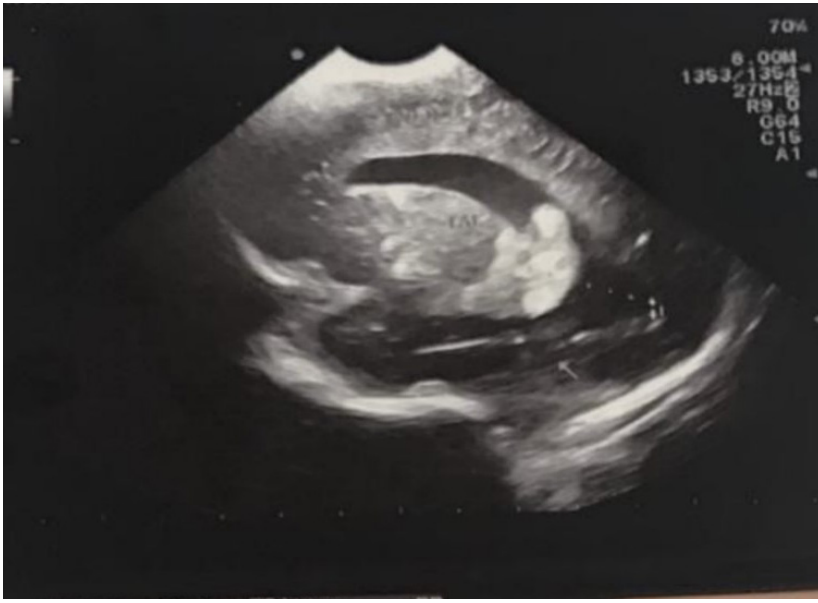

Figura 1. Ecografía transfontanelar sagital

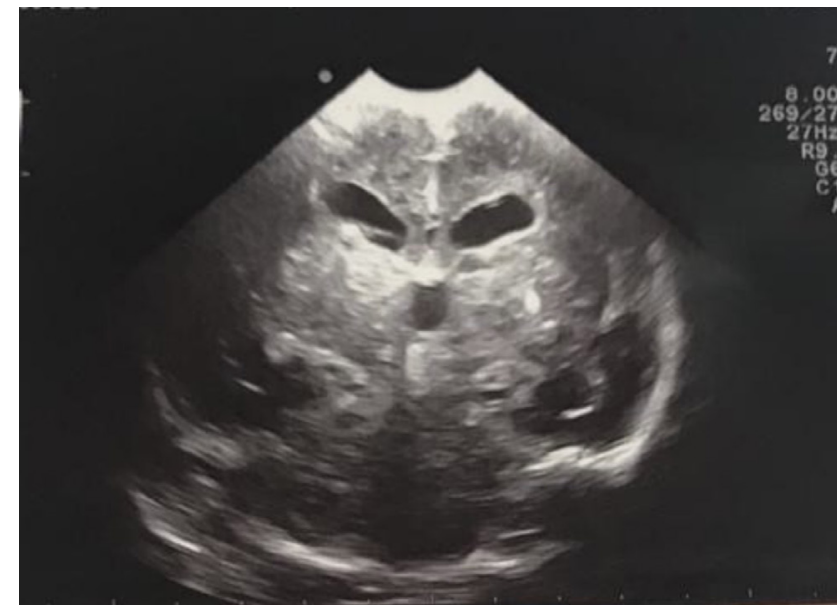

Figura 2. Ecografía transfontanelar coronal

Tabla 3. Análisis de los reportes encontrados en la revisión (* reporte propio)

\begin{tabular}{|c|c|c|c|c|c|c|c|c|c|c|}
\hline $\begin{array}{l}\text { No }^{\circ} \\
\text { Referen- } \\
\text { cia }\end{array}$ & $\begin{array}{l}\text { Edad de } \\
\text { la madre }\end{array}$ & $\begin{array}{l}\text { Antecedente } \\
\text { materno de } \\
\text { leptospi- } \\
\text { rosis }\end{array}$ & $\begin{array}{l}\text { Resultado } \\
\text { del emba- } \\
\text { razo }\end{array}$ & $\begin{array}{l}\text { Ictericia } \\
\text { neonatal }\end{array}$ & $\begin{array}{l}\text { Germen } \\
\text { aislado en } \\
\text { el neonato }\end{array}$ & $\begin{array}{c}\text { Confirmación } \\
\text { del diagnóstico } \\
\text { de leptospirosis } \\
\text { neonatal }\end{array}$ & $\begin{array}{l}\text { Lugar de } \\
\text { aislamiento } \\
\text { de leptos- } \\
\text { pira }\end{array}$ & Manejo & $\begin{array}{c}\text { Asociación } \\
\text { a signos/ } \\
\text { síntomas } \\
\text { atípicos }\end{array}$ & $\begin{array}{l}\text { Resultado } \\
\text { final }\end{array}$ \\
\hline 5 & 27 & $\begin{array}{l}\text { Sí (último } \\
\text { trimestre) }\end{array}$ & $\begin{array}{c}\text { Parto } \\
\text { prematuro }\end{array}$ & No & L. canicola & Sí & N.A & $\begin{array}{l}\text { Tratamien- } \\
\text { to de la } \\
\text { infección y } \\
\text { seguimiento } \\
\text { durante } 10 \\
\text { años al niño }\end{array}$ & N.A & $\begin{array}{l}\text { Recién naci- } \\
\text { do vivo }\end{array}$ \\
\hline 10 & 33 & $\begin{array}{l}\text { Sí (último } \\
\text { trimestre) }\end{array}$ & $\begin{array}{l}\text { Parto a } \\
\text { término }\end{array}$ & $\begin{array}{l}\text { Sí (secun- } \\
\text { daria a } \\
\text { incompa- } \\
\text { tibilidad } \\
\text { ABO) }\end{array}$ & N.A & No & N.A & $\begin{array}{l}\text { Tratamiento } \\
\text { de ictericia } \\
\text { y referencia } \\
\text { a la madre a } \\
\text { infectología }\end{array}$ & Ictericia & $\begin{array}{l}\text { Recién naci- } \\
\text { do vivo }\end{array}$ \\
\hline 11 & 28 & $\begin{array}{l}\text { Sí (último } \\
\text { trimestre) }\end{array}$ & $\begin{array}{l}\text { Parto a } \\
\text { término }\end{array}$ & No & N.A & No & N.A & $\begin{array}{c}\text { Atención } \\
\text { inmediata y } \\
\text { alta a las } 24 \\
\text { horas }\end{array}$ & N.A & $\begin{array}{l}\text { Recién naci- } \\
\text { do vivo }\end{array}$ \\
\hline * & 19 & $\begin{array}{l}\text { Sí (primer } \\
\text { trimestre) }\end{array}$ & $\begin{array}{l}\text { Parto a } \\
\text { término }\end{array}$ & Sí & N.A & $\begin{array}{l}\text { No (solo } \\
\text { sospecha } \\
\text { clínica) }\end{array}$ & N.A & $\begin{array}{l}\text { Ingreso a } \\
\text { UCIN Venti- } \\
\text { lación mecá- } \\
\text { nica Manejo } \\
\text { del shock } \\
\text { séptico }\end{array}$ & $\begin{array}{l}\text { Plaqueto- } \\
\text { penia Pe- } \\
\text { tequiasMi- } \\
\text { crocefalia } \\
\text { Hemorra- } \\
\text { gia Insu- } \\
\text { ficiencia } \\
\text { respiratoria }\end{array}$ & $\begin{array}{c}\text { Fallecimiento } \\
\text { a los } 2 \text { días } \\
\text { por sepsis } \\
\text { (sospecha } \\
\text { clínica de } \\
\text { leptospirosis } \\
\text { congénita) }\end{array}$ \\
\hline
\end{tabular}




\section{DISCUSIÓN}

Nuestro estudio tuvo como objetivo principal el abordaje terapéutico de las complicaciones de un recién nacido con antecedente materno principal de leptospirosis. Aunque la evidencia refiere que es más probable que ocurra aborto espontáneo en el primer trimestre del embarazo, no ha ocurrido así en nuestro caso. Además, hasta el fallecimiento del recién nacido, no se aplicó un método diagnóstico bacteriológico ni de serotipo a la probable leptospirosis congénita.

No se encontró, a priori, información para fundamentar la leptospirosis congénita, por lo que se procedió a elaborar una estrategia de búsqueda utilizando lenguaje estructurado. El criterio de búsqueda sistemática fue “(Leptospirosis OR Leptospira Infection OR Mud Fever OR Stuttgart Disease) AND (neonate OR newborn)"; y se utilizaron las bases de datos Pubmed, Scopus, Web of science y Scielo. De los resultados preliminares, se filtraron en primera instancia todos los reportes de caso con las variables involucradas (de resultado y población) y se escogieron 69 artículos. Luego se procedió a realizar la selección de los reportes de caso asociados a leptospirosis en el neonato o congénita y se encontraron 3 artículos relacionados a esas variables (Tabla 3) ${ }^{(10,15,16)}$.

La leptospirosis neonatal es infradiagnosticada, y solo se han reportado tres casos encontrados en las principales bases de datos, por lo que el abordaje, diagnóstico y tratamiento no se han estandarizado en el paciente neonatal. En el primer estudio ${ }^{(10)}$, el diagnóstico fue enteramente clínico y no se reportó haber realizado análisis bacteriológico ni serotípico al recién nacido, a pesar de hacer un seguimiento durante 10 años. Sin embargo, destaca la importancia de aislar el germen si se cuenta con un antecedente materno comprobado en cualquier trimestre del embarazo a fin de determinar un foco infeccioso por leptospira. La leptospiremia es indicativo de fase temprana de infección de leptospira, que invade primero la sangre y termina alojándose en órganos diana como riñón, hígado y ojos ${ }^{(17)}$.

Un hecho destacable es que los 3 reportes concluyeron que los recién nacidos sobrevivieron a pesar de que aislaron el germen en la gestante en el último trimestre, en comparación con nuestro caso en que el paciente nació vivo a pesar del antecedente materno de leptospirisis diagnosticada en el primer trimestre. Diversos estudios destacan que uno de los elementos resultantes de la infección por leptospira en la madre gestante, es el aborto espontáneo ${ }^{(18)}$.
En conclusión, aunque el abordaje terapéutico fue evitar la complicación de la insuficiencia respiratoria, aunada al fallo multiorgánico y hemodinámico (motivo por el cual se aplicó una terapia integral en la unidad de cuidados intensivos neonatales), es necesario dar a conocer la importancia del seguimiento epidemiológico cuando se cuenta con un antecedente obstétrico como infección por leptospira. En nuestro caso, el diagnóstico de leptospirosis neonatal o congénita no fue concluyente sino presuntivo, puesto que el niño falleció antes de iniciarse el estudio microbiológico para aislar a la bacteria en él.

Contribución de los autores: Luz Cisneros-Infantas, Víctor Peralta-Chávez, han realizado: Concepción y diseño del artículo, recolección de resultados, análisis e interpretación de datos; Redacción del artículo; revisión crítica del artículo; aprobación de la versión final; aporte de pacientes o material de estudio.

Joshuan J. Barboza-Meca ha realizado: Concepción y diseño del artículo; análisis e interpretación de datos; redacción del artículo; revisión crítica del artículo; aprobación de la versión final; aporte de pacientes o material de estudio.

\section{REFERENCIAS BIBLIOGRÁFICAS}

1. Acosta $\mathrm{H}$, Moreno $\mathrm{CH}$, Viáfara D. Leptospirosis. Revisión de tema. Colomb Med. 1994;25(1):36-42.

2. Maze MJ, Cash-Goldwasser S, Rubach MP, Biggs HM, Galloway RL, Sharples KJ, et al. Risk factors for human acute leptospirosis in northern Tanzania. PLoS Negl Trop Dis. 2018;12(6): e0006372.

3. Chinchilla AS, Cordero RB, Bolaños ES. Leptospirosis en humanos. Rev Cost de Ciencias Médicas. 1996;17(2):41-60.

4. Schiff SJ, Kiwanuka J, Riggio G, Nguyen L, Mu K, Sproul $E$, et al. Separating Putative Patho-gens from Background Contamination with Principal Orthogonal Decomposition: Evidence for Leptospira in the Ugandan Neonatal Septisome. Front Med. 2016;3:22

5. Bharti AR, Nally JE, Ricaldi JN, Matthias MA, Diaz MM, Lovett MA, et al. Leptospirosis: a zoono-tic disease of global importance. Lancet Infect Dis. 2003;3(12):757-71.

6. Céspedes Z M, Ormaeche M M, Condori P, Balda J L, Glenny A M. Prevalencia de Leptospirosis y factores de riesgo en personas con antecedentes de fiebre en la Provincia de Manu, Madre de Dios, Perú. Rev Peru Med Exp Salud Publica. 2003;20(4):80-185.

7. Céspedes Z M, Balda J L, González Q D, Tapia L R. Situación de la leptospirosis en el Perú 1994-2004. Rev Peru Med Exp Salud Publica. 2006;23(1):56-66.

8. Céspedes Z M, Fernández C R, Rimarachín D R, Taipe S H, Cenepo T J, Mori y Gonzales M, et al. Leptospirosis: Una enfermedad zoonótica hiperendémica en la provincia de Coronel Portillo. Ucayali, Perú. Rev Peru Med Exp Salud Publica. 2004;21(2):6270.

9. Ministerio de Salud. Sala situacional. Número de casos de leptospirosis 2013-2018. Lima; Centro Nacional de Epidemiologia, Prevención y Control de Enfermedades. 
10. Shaked Y, Shpilberg O, Samra D, Samra Y. Leptospirosis in pregnancy and its effect on the fetus: case report and review. Clin Infect Dis. 1993;17(2):241-3.

11. Faruque LI, Zaman RU, Gurley ES, Massung RF, Alamgir ASM, Galloway RL, et al. Prevalence and clinical presentation of Rickettsia, Coxiella, Leptospira, Bartonella and chikungunya virus in-fections among hospital-based febrile patients from December 2008 to November 2009 in Bang-ladesh. BMC Infect Dis. 2017;17(1):141

12. Schelotto F, Hernández E, González S, del Monte A, Ifran S, Flores $\mathrm{K}$, et al. A ten-year follow-up of human leptospirosis in uruguay: An unresolved health problem. Rev Inst Med Trop Sao Paulo. 2012;54(2):69-75.

13. De Oliveira D, Figueira CP, Zhan L, Pertile AC, Pedra GG, Gusmao $I M$, et al. Leptospira in breast tissue and milk of urban Norway rats (Rattus norvegicus). Epidemiol Infect. 2016;144(11):24209.

14. McGovern LM, Boyce TG, Fischer PR. Congenital infections associated with international travel during pregnancy. J Travel Med. 2007;14(2):117-28.

15. Koe SLL, Tan KT, Tan TC. Leptospirosis in pregnancy with pathological fetal cardiotocography changes. Singapore Med J. 2014;55(2):E20-E4.

16. Chedraui PA, San Miguel G. A case of leptospirosis and pregnancy. Archives of gynecology and obstetrics. 2003;269(1):53-4.

17. Martin UO, Sensevy A, Colombo J, Tramontin V. Leptospirosis in the Province of Santa Fe, Ar-gentina. Medicina (B Aires). 2002;62(2):164-8.

18. Hagen RM, Frickmann H, Ehlers J, Krüger A, Margos G, HizoTeufel $C$, et al. Presence of Borrelia spp. DNA in ticks, but absence of Borrelia spp. and of Leptospira spp. DNA in blood of fever patients in Madagascar. Acta Trop. 2018;177:127-34.
Fuentes de financiamiento:

Este artículo ha sido financiado por los autores.

Conflictos de interés:

Los autores declaran no tener ningún conflicto de interés.

\section{Correspondencia:}

Joshuan J. Barboza Meca

Dirección: Calle Juan del Corral 937. Trujillo.

Teléfono: 992108520

Correo electrónico: jbarbozam1@upao.edu.pe

Recibido: 14 de setiembre de 2018 .

Evaluado: 28 de setiembre de 2018 .

Aprobado: 20 de noviembre de 2018.

(c) La revista. Publicado por Universidad de San Martín de Porres, Perú. (c) Br $_{\text {B }}$ Licencia de Creative Commons Artículo en acceso abierto bajo términos de Licencia Creative Commons Atribución 4.0 Internacional. (http://creativecommons.org/licenses/by/4.0/)

\section{ORCID iDs}

Luz Cisneros Infantas

Víctor Peralta Chávez

Joshuan J. Barboza Meca

https://orcid.org/0000-0002-5811-1753 https://orcid.org/0000-0001-8960-6890 https://orcid.org/0000-0002-2896-1407 